\title{
Economic Growth and Endogenous Intergenerational Altruism*
}

\author{
Hillel Rapoport ${ }^{a}$ and Jean-Pierre Vidal $^{b}$ \\ ${ }^{a}$ CREDPR, Department of Economics, Stanford University \\ and Bar-Ilan University \\ ${ }^{b}$ European Central Bank
}

May 2003

\begin{abstract}
The recent literature on the endogenous formation of preferences has emphasized that while some preferences are more conducive to growth than others, economic growth also contributes to the formation of particular tastes (Becker, 1996). In this paper, we construct a neoclassical growth model where intergenerational altruism is endogenous and entails costly sacrifices on the part of parents to acquire such trait. While the acquisition of altruistic traits depends on the economic conditions, altruism determines the level of intergenerational bequests and ultimately the accumulation of physical capital and economic growth. We derive three main results from this general equilibrium framework. First, we show that individuals accumulate altruism in the long run whenever the 'marginal degree of altruism' is sufficiently high. Second, we find that the endogenous formation of altruism is more likely to occur at later stages of economic growth. Finally, we show that low interest rates are correlated with altruistic behavior; this is in contrast to previous research in a partial equilibrium framework (Mulligan, 1997).
\end{abstract}

JEL Classification numbers: D19, D90

Keywords: Altruism, Economic Growth

${ }^{*}$ Corresponding author: Jean-Pierre Vidal, European Central Bank, Kaiserstrasse 29, Frankfurt-amMain, Germany. Email: jean-pierre.vidal@ecb.int. The views expressed in this paper are those of the authors and do not necessarily reflect those of the European Central Bank (ECB). We are grateful to Bertrand Crettez, Anjini Kochar, Casey Mulligan, Philippe Michel and Emmanuel Thibault for helpful comments. The usual disclaimer applies. 


\section{Introduction}

The complex interdependencies between preferences and economic growth were well recognized by classical economists and philosophers. In their view, the institutions of a market economy (e.g., private property, individual responsibility) were desirable mainly because, beyond their expected outcome in terms of efficiency, these institutions were instrumental to the development of a set of preferences and attitudes that enhance economic prosperity and social harmony. ${ }^{1}$ In the case of parental altruism as well, classical economists believed that altruism was endogenous and entailed costly sacrifices on the part of parents to acquire such trait. Becker (1996) and Mulligan (1997) have pioneered a recent revival of these ideas. They explained that while some preferences are more growth-enhancing than others, on the other hand, economic growth modifies the incentive structure faced by individuals when "choosing" their own preferences and thus contributes to the formation and selection of particular tastes. For example, Becker (1996, p. 19) noted that "Preferences and the rates of economic growth are correlated because [some] tastes ... are more conducive to rapid economic growth. However, the endogeneity of preferences implies that growth and preferences are related also because economic outcomes help form tastes." The approach was first applied to two types of preferences that have long been recognized as critical for growth: time preference (Becker and Mulligan, 1997; Michel and Vidal, 2003) and the formation of parental altruism (Mulligan, 1997).

The introduction of intergenerational altruism in macroeconomic models dates back to the 1970s. Barro (1974) extended Becker's idea of the neutrality of transfers within the family (Becker, 1974) to argue that public debt does not affect the economic equilibrium owing to offsetting private transfers between generations. Barro's debt neutrality proposition has spurred a strand of research aimed at clarifying the exact conditions under which ricardian equivalence applies. Barro's analysis is based on the assumption that successive generations share a particular form of altruism, whereby each generation is only directly concerned for its immediate descendants. All generations are therefore linked together by a recursive altruistic relation. Other forms of altruism have also been put forward in the literature and often referred to as ad hoc forms of altruism insofar as parents' utility does not directly depend on their children's utility. Since such ad hoc forms of altruism allow for modeling the relationships between successive generations at a lower technical cost, most recent advances in the field of intergenerational altruism and economic growth have been achieved using models of ad hoc altruism rather than dynastic models $\grave{a} l a$ Barro. $^{2}$ For example, a growing literature now focuses on how parents' behavior affects the preferences of their children owing to intergenerational taste externalities (Bisin and Verdier, 2000, de la Croix and Michel, 2001).

It is only very recently, however, that altruism has (again) been considered as a trait parents can acquire. ${ }^{3}$ The endogenous preferences approach not only recognizes that parents care for the economic fate of their children, and make choices that affect their

\footnotetext{
${ }^{1}$ Tocqueville (1840, p. 527) remarked that "The principle of self-interest produces no great acts of self-sacrifice ... but it disciplines a number of persons in habits of regularity, temperance, moderation, foresight, self-command; and if it does not lead men straight to virtue by the will, it gradually draws them in that direction by their habits" (quoted by Becker, 1996, p. 18). See Hirschman (1977) on classical arguments in favor of a market society, and Bowles (1998) for a review of the recent literature on the impact of markets on preferences formation.

${ }^{2}$ See Michel, Thibault and Vidal (2003) for a recent survey on intergenerational altruism in models of economic growth.

${ }^{3}$ See Mulligan (1997, chapter 10) on classical economists' views on altruism.
} 
children's well-being, it goes one step further in that it extends the domain of parental choice to include the level of altruism a parent would want to have. This implies that parents invest resources (mainly time) to shape their own preferences towards more concern for their children when they recognize that such a change would raise their own utility. This is a cognitive process similar in nature to the choice of one's preferences for drugs when the effects of addiction are fully anticipated (Becker and Murphy, 1988). As Mulligan put it, (1997, p. 76), "the point ... is to allow adults to affect the kind of parents they will be. Do they want to be altruistic parents who place a lot of weight on their child's success or do they want to be less altruistic parents whose personal consumption is their main priority?'. In other words, it is because they rationally anticipate the effects of their actions on their future preferences and life-cycle utility that parents purposefully accumulate intergenerational altruism through the purchase of child-oriented goods (e.g., time spent interacting with their children). ${ }^{4}$ An important element in this rationale is that accumulating concern for one's children is costly (for if it was not, the economic approach could be applied to the consequences of given preferences but not to their formation). This means that the resources invested in acquiring altruism are distracted from other possible uses (for example, accumulating altruism comes at the price of having less time available for either leisure or work), and implies that a change in the relative price of child-oriented goods affects the degree at which altruism is accumulated as well as the consumption of the other goods entering in the parents' extended utility function (typically, the parents' consumption level and the size of the bequest passed on to the next generation).

Using this perspective, Mulligan (1997) suggested that new economic insight may be obtained through analyzing issues such as fertility, income distribution, fiscal policy and economic growth against a background of endogenous intergenerational altruism. Mulligan's analysis is based on a partial equilibrium framework; as such, this approach cannot fully capture the dynamic relationships between economic growth and the evolution of altruistic behavior. The purpose of this paper is to extend Mulligan's model of endogenous altruism to a fully-fledged neoclassical framework by developing a general equilibrium model in which intergenerational altruism, interest rates and rates of economic growth are jointly determined. More precisely, we use a neoclassical growth model of successive generations in which each generation consumes, accumulates concern for children, and leaves bequests. A particular form of ad hoc altruism is assumed, with individuals endogenously choosing the ratio between their own life-cycle consumption and the bequest passed on to their heirs. The production side is given by a standard Cobb-Douglas technology, while demand is obtained, in line with Mulligan (1997), by maximizing the utility of a representative consumer with Leontieff preferences over consumption and bequests.

We obtain three main results. First, it is shown that individuals accumulate altruism in the long run whenever the rate at which concern is accumulated - the marginal degree of altruism - exceeds a certain threshold, which depends on both the endowed degree of altruism and technological parameters. Second, we find that the endogenous formation of altruism is more likely to occur at later stages of economic growth. Finally, our results point to a negative relationship between altruism and interest rates, in contrast to the positive relationship found in the case of exogenous interest rates (Mulligan, 1997).

The remainder of this paper is organized as follows. In Section 2, we briefly review

\footnotetext{
${ }^{4}$ Child-oriented goods or activities also include other time and mental effort spent by parents anticipating and appreciating the success that children will someday enjoy as a result of parental transfers of money, schooling, and other resources (Mulligan, 1997, p. 77).
} 
some stylized facts that the theory contributes to explain alongside more traditional explanations. In Section 3 we set up a neoclassical growth model of endogenous altruism, and establish a sufficient condition under which the dynamics are globally concave. Section 4 is devoted to the dynamics of economic growth with endogenous intergenerational altruism. Section 5 concludes.

\section{Background}

The results outlined above are consistent with historical and cross-country evidence on the relationships between altruism, demand for child-oriented goods and stages of economic growth.

From an historical perspective, the view according to which parental altruism is affected by changes in the economic environment is well documented in the case of nineteenth century Europe. We will illustrate this using a particular type of child-oriented good, the time spent with children, for a particular country, France. As explained by Brezis (2002), at the onset of the industrial revolution, most Parisian women used to send their children for nursing far away from Paris, while they could not ignore the much higher mortality rates among children raised out of the parental home. Out of the 21,000 children born each year in Paris in the 1780s, 18,000 were sent away to a wet nurse and more than two-thirds did never return. Brezis (2002) also mentions descriptions of women who sent two or three of their children away for nursing, and "although they never returned from nursing at a specific location, still sent their subsequent children to the very same place", and concludes that over the period studied, "parental behavior was not compatible with altruism". These figures are confirmed by many first-hand sources collected by Badinter (1980, pp. 219-23) to document her thesis on the recent evolution of maternal altruism. For example, we learn from these pages that according to Brochard, a well-reputed physician, nearly 20,000 children were "exported" from Paris to the neighboring rural district of Nogent-le-Rotrou during the year 1860, either through placement agencies (for the majority of them) or directly by the parents themselves or by public authorities; Brochard sets the survival rate of these children at 25\%. The French moralist Sarcey reaches the same estimate for the 1850s. It is also noteworthy that the number of abandoned children in France started decreasing only in the last decades of the nineteenth century, and it has been estimated that 30 to $40 \%$ of the children born in the largest cities of France were still sent out to a wet-nurse in the early twentieth century. Needless to say, similar figures may be found for eighteenth century England and other European countries prior to - or at early stages of - industrialization.

In today's developing countries, there is also evidence that parents-children relationships do not involve the type of child-oriented goods that are conducive to the joint accumulation of concern and wealth we consider in this paper. In their comparative study of seven developing countries, Brown and Haddad (1995) report that the time spent with children does never exceed two hours per day and is in most cases lower than one hour a day for women, while few men - if any - engage in child rearing activities in all seven countries. This low absolute level may be attributed to child-rearing activities involving members of the extended family, while behavioral differences between men and women may be due to the intra-household allocation of time along gender lines or to differences in the concern for children between mothers and fathers. Indeed, one established result of the recent intrahousehold resource allocation literature is that the relative power of women 
is of considerable importance for children's health and other outcomes. For example, in the case of Indonesia, it has been shown that as the share of household assets owned by the mother at marriage increases, the prevalence of child labor decreases (Galasso, 1999). Similarly, the share of earned and/or non-wage income in the mother's hands significantly increases the budget share dedicated to children's goods (Thomas, 1990, Duflo and Udry, 2001). Such differences in behavior between mothers and fathers tend to disappear in more economically advanced societies, as if parental preferences were converging towards a higher and equallyshared level of altruism.

Observed changes in the quality of child-rearing activities also suggest that there is some formation of preferences at work in the course of the economic development process. For example, observing family practices in Bhubaneswar, the capital of the State of Orissa in North-Eastern India, Seymour (1999) notes striking differences in this respect between the residents of the old-town and of the new town: "[differences in the] patterns of caretaking are even more striking if one considers the concerted efforts made by adults to teach young children specific skills or to give them information or to entertain them in some special way - what I have called 'stimulating acts'. In the New Capital, the principal agents of such stimulation were mothers, whereas in the Old Town, predictably, such behavior was well dispersed among extended kin and neighbors. Not only was the New Capital child's biological mother more actively engaged in efforts to stimulate him, but stimulating acts occurred more frequently ... Mothers in the New Capital played with their children, taught words and motor skills to them, sometimes tutored them, and encouraged them in their activities with significantly greater frequency than did the mothers and extended kin of children in the Old Town" (Seymour, 1999, p. 126). Another interesting comparison made by Seymour (1999, pp. 158-59) and based on income status rather than residence shows that in low-status households $93 \%$ of all 'nurturant acts' are directed towards children under age three whereas in middle and upper-status households, the comparable figure is $59 \%$ (29\% and $12 \%$ for 3-6 and 6-10 year-olds respectively). This shows that intergenerational altruism not only manifests itself at a higher level among the middle and upper class, but also that for these middle and upper classes, it extends itself beyond the first years of life, after the child's survival is assured.

Finally, the fact that education expenditure as a share of GDP increases with the level of economic development is also consistent with the endogenous accumulation of altruism. Indeed, public education spending as a share of GDP rises from less than $3 \%$ of GDP in low-income countries to more than 5\% in high-income countries (World Bank, 2001). Again, this may be attributed to a number of causes - alleviation of liquidity constraints, or simply higher returns to schooling in richer countries. However, it is noteworthy that maternal time spent on helping children with school work shows a strong positive correlation with maternal schooling (despite the higher opportunity cost of educated mothers' time). In rural India, only $1 \%$ of illiterate mothers report such time, a percentage that rises to $15 \%, 31 \%$ and $41 \%$ for mothers with respectively primary, middle and higher schooling (Kochar, 2002). In a similar vein but controlling for income, Malathy (1992) and Behrman et al. (1999) report a significant positive impact of maternal literacy on the time spent with children respectively in urban and rural India. This may be due to the higher productivity of educated parents in the production of education, but is also compatible with higher levels of intergenerational altruism at higher levels of education, income and wealth. Indeed, Malathy (1992) also finds that an increase in the household's assets leads to an increase in the time spent teaching children at the expenses of all other non-market activities. 
This conjecture is corroborated by recent demographic studies in economically-advanced societies (e.g., Bianchi, 2000, Sandberg and Hoffert, 2001), showing that the time spent interacting with one's children represents a substantial and increasing fraction of parents' time. Interestingly, the time spent by mothers has remained almost constant (if not increasing) since the 1960s despite the dramatic rise in women's labor force participation, and fathers are spending more time with their children than in the past, resulting in an overall increase in the time dedicated by parents to their children. These studies agree on their interpretations of the results, which are attributed to behavioral changes due to concern for children's well-being and development rather than to income effects or structural demographic changes such as mothers' employment and education levels, family size, or prevalence of single parenthood.

\section{The model}

\subsection{Individuals}

We adapt Mulligan's way of modeling endogenous altruism to a growing economy (Mulligan 1997, chapter 4). Mulligan assumes that preferences are L-shaped in the parental consumption-child consumption plane, and convincingly explains why this assumption is a useful simplification; allowing for substitution effects would only mitigate the results. Therefore, and in line with Mulligan, we assume that parents' preferences are L-shaped in the parental consumption-bequest plane. This assumption fits better a model of successive generations in which each generation accumulates altruism and bequeaths than an approach assuming that preferences are defined over the consumptions of successive generations. The reason is that under Mulligan's formulation of the utility function a parent's decision to leave a bequest would, in a dynamic economy, depend on their own children's decision to leave a bequest, thereby nesting the choices of successive generations. The model could be solved by assuming a Nash equilibrium between successive generations. However, our approach of modeling preferences in the consumption-bequest plane saves us the cost of such intricacies without affecting the main thrust of our results.

A parent's concern for a child's welfare is assumed to depend on the amount of resources, $q_{t}$, directed toward the accumulation of altruism, or in other words spent on child-oriented goods or activities. As discussed above, given the amount of accumulated altruism, $f\left(q_{t}\right)$, a parent's indifference curves are assumed to be L-shaped in the parental consumption-bequest plane, $\left(c_{t}, x_{t}\right)$.

$$
U\left(c_{t}, x_{t}, q_{t}\right)=\min \left\{f\left(q_{t}\right) c_{t}, x_{t}\right\}
$$

Assumption 1: For all $q \geq 0, f(q)>0, f^{\prime}(q)>0$, and $f^{\prime \prime}(q) \leq 0$.

The higher the concern for a child, the higher the ratio of bequest to parental consumption. The underlying assumption is that parental consumption and bequest are complementary goods. As explained in the introduction, accumulating altruism is costly and the resources devoted to the accumulation of altruism reduce the parental consumptionbequest possibility set. A parent supplies one unit of labor, earns the market wage $w_{t}$, inherits $R_{t} x_{t-1}$, consumes $c_{t}$, bequeaths $x_{t}$, and devotes $q_{t}$ to the accumulation of altruism:

$$
\omega_{t} \equiv R_{t} x_{t-1}+w_{t}=c_{t}+x_{t}+q_{t}
$$


According to the utility function $U$ a parent chooses $c_{t}$ and $x_{t}$ in a fixed proportion that depends on $q_{t}$ :

$$
\frac{x_{t}}{c_{t}}=f\left(q_{t}\right) ; c_{t}=\frac{\omega_{t}-q_{t}}{1+f\left(q_{t}\right)} ; x_{t}=\frac{f\left(q_{t}\right)\left(\omega_{t}-q_{t}\right)}{1+f\left(q_{t}\right)}
$$

We can therefore derive an equivalent reduced form utility function in terms of $q_{t}$ :

$$
H\left(q_{t}\right)=\frac{f\left(q_{t}\right)\left(\omega_{t}-q_{t}\right)}{1+f\left(q_{t}\right)}
$$

whose maximizer is the optimal amount of resources devoted to the accumulation of altruism. Under this set of assumptions, we show that investment in altruism occurs only if parents' life-cycle income is above a certain wealth threshold (or, in this model, above a certain threshold of disposable income).

Proposition 1. : If $\omega_{t}>\frac{f(0)(1+f(0))}{f^{\prime}(0)} \equiv \bar{\omega}$, there exists a unique $\left.q_{t}^{*} \in\right] 0, \omega_{t}[$ solution to the parent's maximization problem. If $\omega_{t} \leq \bar{\omega}$, the solution to the parent's maximization problem is $q_{t}=0$.

Proof: $H^{\prime}(q)$ is of the same sign as

$$
G(q) \equiv f^{\prime}(q)(\omega-q)-f(q)(1+f(q))
$$

One has:

$$
G^{\prime}(q)=-f^{\prime}(q)+(\omega-q) f^{\prime \prime}(q)-f^{\prime}(q)(1+f(q))-f^{\prime}(q) f(q)<0
$$

Note that $q \in[0, \omega]$ and,

$$
G(\omega)=-f(\omega)(1+f(\omega))<0 ; G(0)=\omega f^{\prime}(0)-f(0)(1+f(0))
$$

Clearly, there exists a unique $\left.q^{*} \in\right] 0, \omega\left[\right.$ satisfying $H^{\prime}\left(q^{*}\right)=0$ if and only if $G(0)>0$. The optimal choice is $q^{*}=0$ if and only if $G(0) \leq 0$.

Hence, parents accumulate altruism if and only if they are sufficiently wealthy (i.e., characterized by a life-cycle income exceeding the threshold level $\bar{\omega}$ ).

The solution to the individual consumption-bequest choice is illustrated by Figure 1. The function $H(q)$ is represented in the lower part of the figure; the point $\omega$ corresponds to $q=0$ and the point 0 to $q=\omega . H(q)$ is maximized for $q=q^{*}$ in the example at hand. Point $I$ is the consumption-bequest choice that would be selected by an individual who is unable to accumulate altruism (e.g., $\left.H^{\prime}(q)=0\right)$. The line $(0 A)$ is the ray of preferred proportion for such an individual. Comparing this allocation with the allocation $\left(c^{*}, x^{*}\right)$ makes clear the impact of endogenous altruism. The individual who accumulates altruism is characterized by a ray of preferred proportion between bequest and consumption that is steeper $(0 B)$. He or she leaves a higher bequest and consumes a lesser amount of standard goods, which are substituted for by the consumption of child-oriented goods. 
Henceforth we consider a linear technology of accumulation of altruism:

$$
f(q)=\beta q+\gamma ; \beta>0 ; \gamma>0
$$

We refer to $f(q)$ as the level of intergenerational altruism, while $\gamma$ and $\beta$ are respectively the endowed degree of intergenerational altruism and the marginal degree of altruism. This specification ${ }^{5}$ will allow us to fully characterize analytically the solution of the individual maximization program and later on the dynamics of the economy. In particular, the threshold level of wealth above which individuals accumulate altruism translates into a threshold level of the marginal degree of altruism.

The solution to a parent's maximization problem depends on his or her life-cycle income (recall that this consists of both labor income and inherited wealth) and the parameters $\beta$ and $\gamma$. According to Proposition 1, a parent does not spend resources on child-oriented goods and, hence, does not accumulate altruism, if $\omega_{t} \leq \bar{\omega}=\frac{\gamma(1+\gamma)}{\beta}$. In this case, the solution to a parent's maximization problem is:

$$
q_{t}=0 ; x_{t}=\frac{\gamma \omega_{t}}{1+\gamma} ; c_{t}=\frac{\omega_{t}}{1+\gamma}
$$

As long as parents are not sufficiently wealthy to spend resources on child-oriented goods, the ratios of bequest and consumption to disposable income are constant. This can be attributed to the assumption of Leontieff preferences. On the other hand, a parent who is sufficiently wealthy (i.e., for whom $\omega_{t}>\bar{\omega}$ ) accumulates altruism. In this case, the solution to a parent's maximization problem is:

$$
\begin{gathered}
q_{t}=\frac{\left(\beta \omega_{t}+1+\gamma\right)^{1 / 2}-(1+\gamma)}{\beta} \\
x_{t}=\frac{\left(\left(\beta \omega_{t}+1+\gamma\right)^{1 / 2}-1\right)^{2}}{\beta} \\
c_{t}=\frac{\left(\beta \omega_{t}+1+\gamma\right)^{1 / 2}-1}{\beta}
\end{gathered}
$$

When parents spend resources on child-oriented goods, the share of bequests, consumption and child-oriented expenditures are no longer constant and are affected by the dynamics of disposable income. Not surprisingly, the amount of child-oriented goods is a decreasing function of the endowed degree of altruism.

\subsection{Production}

Production occurs according to a Cobb-Douglas technology using two inputs, capital $K_{t}$ and labour $L_{t}$ : $f\left(k_{t}\right)=A k_{t}^{\alpha}$, where $k_{t} \equiv K_{t} / L_{t}$ stands for the capital-labor ratio, $A>0$, and $\alpha \in] 0,1[$. Markets are competitive so that production factors are paid their marginal product:

$$
w_{t}=(1-\alpha) A k_{t}^{\alpha} ; R_{t}=\alpha A k_{t}^{\alpha-1}
$$

Capital fully depreciates during the production process.

\footnotetext{
${ }^{5}$ In line with the literature on inherited tastes, one could argue that altruistic traits are transmitted from parents to children. The endowed degree of altruism would then be modeled as a state variable depending for example on the degree of altruism of the parents. This would not modify our analysis of individual choices, as the endowed degree of altruism is considered as given by children.
} 


\subsection{Dynamics}

Parents spend resources on child-oriented goods and accumulate altruism whenever their wealth $\omega_{t}$ exceeds a threshold level $\bar{\omega}$. This has strong implications for the dynamics of the economy; the disposable income or wealth threshold relates to a threshold level of the capital-labor ratio along the dynamic path. There is no population growth, $L_{t}=N$. Individuals live one period and savings are equal to inherited wealth in this model, where bequests are the main engine of economic growth:

$$
k_{t+1}=x_{t}
$$

Individuals' disposable income is thus equal to output:

$$
\omega_{t}=w_{t}+R_{t} x_{t-1}=w_{t}+R_{t} k_{t}=A k_{t}^{\alpha}
$$

Individuals accumulate altruism whenever the capital-labor ratio exceeds a threshold level $\widetilde{k}$ :

$$
\omega_{t}>\frac{\gamma(1+\gamma)}{\beta} \Leftrightarrow k_{t}>\left(\frac{\gamma(1+\gamma)}{A \beta}\right)^{1 / \alpha} \equiv \widetilde{k}
$$

This threshold is positively related to the endowed degree of intergenerational altruism and negatively to the marginal degree of altruism. The scale factor impacts negatively on this threshold, which indicates that economies with higher total factor productivity are more likely to spend on child-oriented goods. The dynamics of the economy can be expressed as follows:

$$
k_{t+1}=G\left(k_{t}\right)=\left\{\begin{array}{c}
\frac{\gamma}{1+\gamma} A k_{t}^{\alpha} \equiv G_{1}\left(k_{t}\right) \text { if } k_{t} \leq \widetilde{k} \\
\frac{1}{\beta}\left[\left(\beta A k_{t}^{\alpha}+1+\gamma\right)^{1 / 2}-1\right]^{2} \equiv G_{2}\left(k_{t}\right) \text { if } k_{t}>\widetilde{k}
\end{array}\right.
$$

The dynamics are continuous and monotonically increasing. The dynamic map satisfies: $k_{t} \rightarrow+\infty \lim \frac{G\left(k_{t}\right)}{k_{t}}=0<1$ and $k_{t} \rightarrow 0 \lim G^{\prime}\left(k_{t}\right)=+\infty>1$. The dynamics therefore converge to a steady-state equilibrium. The dynamic map may not be globally concave, and the steady state not unique; concavity fails on $[\widetilde{k},+\infty[$ for some values of the parameters. Since we are not primarily interested in this possibility, we shall pursue the analysis under the assumption that the dynamics are globally concave and therefore experience a unique globally stable steady-state equilibrium. Proposition 2 states a sufficient condition under which this is valid. The proof is given in the appendix.

Proposition 2. : If the capital share is below 1/2 the economy experiences a unique globally stable steady-state equilibrium. Individuals accumulate altruism in the long run if and only if the marginal degree of altruism is sufficiently high, that is, if $\beta>$ $\left(\frac{1+\gamma}{A}\right)^{\frac{1}{1-\alpha}} \gamma^{\frac{1-2 \alpha}{1-\alpha}}=\bar{\beta}$.

A milder sufficient condition for uniqueness and global stability (see appendix) is $\alpha<2 / 3$ and $\gamma>\left(\frac{\alpha}{1-\alpha}\right)^{1 / 2}-1$; both conditions are satisfied if the capital share is below $1 / 2$ for any positive endowed degree of altruism. When global concavity fails, the economy may experience multiple steady states and hence poverty traps as in Azariadis and Drazen (1990). We rule out this case and focus on the relationship between economic growth and endogenous formation of altruism. 


\section{Economic growth and the formation of intergenerational altru- ism}

Earlier stages of economic development are associated with low levels of accumulation of physical capital, low incomes and high interest rates. Low incomes, as stressed above, are associated with no spending on child-oriented goods and no endogenous formation of altruism. Only when economic development is sufficiently advanced do individuals allocate a share of their resources to child-oriented goods, thereby endogenously accumulating altruism. In the framework of a partial equilibrium model in which the rate of interest is set exogenously, Mulligan (1997) finds that "child-oriented resources are normal goods" and that "a higher interest rate encourages the purchase of child-oriented resources" (see his propositions 1 and 3, page 126). The later conclusion, which is clearly true in a partial equilibrium approach, is at odds with what one might expect from the patterns of economic development. In a model with a neoclassical technology of production a lower interest rate encourages the accumulation of altruism. Were prices exogenous in our model, as in the small open economy case, a higher interest rate would increase parental income and therefore the amount spent on child-oriented goods (which are normal goods). Endogenizing factor prices brings about a general equilibrium effect according to which high interest rates are associated with low levels of capital accumulation and income. The next proposition describes the pattern of economic growth with endogenous altruism, assuming that the marginal degree of altruism is sufficiently high to trigger endogenous formation of altruism $(\beta>\bar{\beta})$

Proposition 3. : At earlier stages of economic growth, individuals are constrained with respect to spending on child-oriented goods and there is no endogenous formation of altruism. Along the growth path, the endogenous formation of altruism starts once the capital-labor ratio exceeds a threshold level triggering spending on child-oriented goods, and speeds up economic development.

We illustrate our theoretical results with a numerical exercise, sketching the dynamics of the economy. As we are mainly interested in the effects of endogenous altruism on economic growth, Figure 2 represents the evolution of capital, consumption and bequests as a percentage difference with respect to the baseline dynamics of an economy in which there is no possibility to accumulate altruism (i.e., an economy where $\beta$ is equal to 0 ). We set the capital share to $1 / 3$ and the scale factor to 1 . The population is normalized to 1. The endowed degree of altruism was set to $1 / 4$, which is consistent with a saving ratio of $20 \%$ (here the saving ratio is identical to the bequest ratio) and a consumption ratio of $80 \%$ in the economy with a zero marginal degree of altruism. The marginal degree of altruism, $\beta$, was set at 0.3 above the threshold triggering endogenous formation of altruism $^{6}$. The initial capital-labor ratio represented $1 \%$ of the capital threshold above which individuals start to accumulate altruism.

\section{[INSERT FIGURE 2 HERE]}

At the early stages of economic development (in this example up to period 1), individuals do not spend on child-oriented goods and their degree of altruism remains at

\footnotetext{
${ }^{6}$ This threshold is about 0.7 for the value of parameters at hand, so that $\beta$ is close to 1 .
} 
its endowed level, $\gamma$. As from period 1 in this simulation exercise, they start to consume child-oriented goods, leading to a sharp decrease in the consumption of other goods. Standard consumption goods and child-oriented goods are substitute. This also triggers an increase in the level of bequests, as more altruistic individuals devote a higher share of their disposable income to bequests. Since bequests are the main engine of growth in this stylized model, this leads to a subsequent increase in the capital-labor ratio, thereby speeding up economic development. With the value of parameters at hand, the consumption of standard goods is about $15 \%$ lower than in the baseline model and the capital-labor ratio $4 \%$ above baseline in the steady state. It should be noted that total consumption, defined as the sum of standard and child-oriented goods, is higher in the economy with endogenous formation of altruism.

\section{Conclusion}

Modern neoclassical economics emphasize that behavioral changes generally result from changes in the economic environment; and indeed, economic growth strongly impacts on people's observed behavior by alleviating borrowing constraints and easing access to education or healthcare. However, this may be only part of the picture, as economic growth also brings about changes in individuals' attitudes and values. In the case of intergenerational altruism, this is illustrated, for example, by the fact that parents in early nineteenth century's Europe or in today's poor countries spend only a fraction of their time interacting with their children, while in economically-advanced societies parents now share a substantial and still increasing amount of their time with their children.

As a complementary explanation, we proposed a simple general equilibrium model of endogenous intergenerational altruism and growth. Our main theoretical result is that parents accumulate altruism only beyond a certain threshold level of wealth. The reason is that wealth is an argument in cultivating a taste or concern for children, thereby influencing altruistic behaviors (e.g., bequests). And since capital formation is one aspect of wealth, altruistic behavior is more likely in advanced societies that have a sufficiently high level of capital formation. As a corollary, lower interest rates, which result of high levels of capital accumulation, are correlated with altruistic behavior; this contrasts with Mulligan's partial equilibrium result that high interest rates will lead to more purchases of child-oriented goods, and contributes to explain why parents are more likely to behave altruistically in more economically-advanced societies or why resources allocated to child-oriented goods (such as education expenditures or time spent with children) are relatively much higher in developed countries than in developing countries. It should also be noted that our conclusion regarding the impact of the endogenous formation of altruism on growth would not be significantly altered by assuming that the endowed degree of altruism is inherited from one's parents. Earlier stages of economic growth would still be characterized by the absence of endogenous formation of altruism until a sufficient amount of physical capital is accumulated. The endogenous formation of altruism would then speed up growth by modifying the share of bequests to disposable income. However, later stages of economic growth could well be characterized by no further accumulation of altruism, since individuals would benefit from the acquisition of altruistic traits by the previous generations. 


\section{Appendix}

Proof of proposition 2: We first consider the dynamics on $[0, \widetilde{k}]$

$$
G_{1}:[0, \widetilde{k}] \rightarrow\left[0, \frac{\gamma^{2}}{\beta}\right] ; k_{t} \mapsto k_{t+1}=G_{1}\left(k_{t}\right)=\frac{\gamma A}{1+\gamma} k_{t}^{\alpha}
$$

The dynamics are monotonic increasing and globally concave on $[0, \tilde{k}]$ with $k \rightarrow 0 \lim G_{1}^{\prime}(k)=$ $+\infty$. There exists a unique steady state on $[0, \widetilde{k}]$ if and only if $\widetilde{k}-G_{1}(\widetilde{k}) \geq 0 \Leftrightarrow \beta \leq$ $\left(\frac{1+\gamma}{A}\right)^{\frac{1}{1-\alpha}} \gamma^{\frac{1-2 \alpha}{1-\alpha}}$. If this condition holds we denote with $k_{1}$ this steady state without endogenous formation of altruism:

$$
k_{1}=\left(\frac{\gamma A}{1+\gamma}\right)^{\frac{1}{1-\alpha}}
$$

Note that there exists a unique $A=\frac{\gamma(1+\gamma)}{\beta}\left(\frac{\beta}{\gamma^{2}}\right)^{\alpha} \equiv \bar{A}$ such that $k_{1}=\widetilde{k}=G_{1}(\widetilde{k})$.

Let us now consider the dynamics on $[\widetilde{k},+\infty[$. The dynamics are monotonic increasing on $[\widetilde{k},+\infty[$ but not always concave since we have:

$$
\begin{gathered}
G_{2}^{\prime}(k)=\alpha A k^{\alpha-1}\left(1-\left(\beta A k_{t}^{\alpha}+1+\gamma\right)^{-1 / 2}\right)>0 \\
G_{2}^{\prime \prime}(k)=\frac{\alpha A k^{\alpha-2}}{\left(\beta A k_{t}^{\alpha}+1+\gamma\right)^{1 / 2}}\left[(\alpha-1)\left(\left(\beta A k_{t}^{\alpha}+1+\gamma\right)^{1 / 2}-1\right)+\frac{1}{2} \frac{\beta \alpha A k^{\alpha}}{\beta A k^{\alpha}+1+\gamma}\right]
\end{gathered}
$$

Let us define $X=\beta A k^{\alpha}$. Note that $X \in\left[\widetilde{X},+\infty\left[\right.\right.$, where $\widetilde{X}=\gamma(1+\gamma) . G_{2}^{\prime \prime}(k)$ is of the same sign as:

$$
F(X)=(\alpha-1)\left((X+1+\gamma)^{1 / 2}-1\right)+\frac{1}{2} \frac{\alpha X}{X+1+\gamma}
$$

We have:

$$
F^{\prime}(X)=\frac{\alpha(1+\gamma)}{2(X+1+\gamma)^{1 / 2}}\left(\frac{1}{(X+1+\gamma)^{3 / 2}}-\frac{1-\alpha}{\alpha(1+\gamma)}\right)
$$

$F^{\prime}(X)$ is of the same sign as $T(X) \equiv \frac{1}{(X+1+\gamma)^{3 / 2}}-\frac{1-\alpha}{\alpha(1+\gamma)}$. We have: $T^{\prime}(X)<0$ and

$$
F^{\prime}(\tilde{X})<0 \Leftrightarrow 1+\gamma>\left(\frac{\alpha}{1-\alpha}\right)^{1 / 2}
$$

We further have:

$$
F(\widetilde{X})=\frac{\gamma}{2(1+\gamma)}(3 \alpha-2+2 \gamma(\alpha-1))
$$

A necessary condition for the concavity of $G_{2}$ on $[\widetilde{k},+\infty[$ is $F(\widetilde{X})<0$, that is,

$$
1+\gamma>\frac{\alpha}{2(1-\alpha)}
$$


This condition can hold only if $\alpha<2 / 3$ since $\gamma>0$. If $\alpha>2 / 3, F(\tilde{X})>0$ for $\gamma$ sufficiently small and $G_{2}$ fails to be concave. $\alpha<2 / 3$ is therefore a necessary condition for the concavity of $G_{2}$. A sufficient condition for the concavity of $G_{2}$ on $[\widetilde{k},+\infty[$ is $F(\widetilde{X})<0$ and $F^{\prime}(\widetilde{X})<0$, that is:

$$
\alpha<2 / 3 \text { and } \gamma>\left(\frac{\alpha}{1-\alpha}\right)^{1 / 2}-1
$$

The dynamic map is continuous and differentiable on $R^{+}$since $G_{2}(\widetilde{k})=G_{1}(\widetilde{k})=$ $\gamma^{2} / \beta$ and $G_{2}^{\prime}(\widetilde{k})=G_{1}^{\prime}(\widetilde{k})=\alpha \frac{\gamma^{2}}{\beta} \frac{1}{k}$. It results that the dynamic map is globally concave on $R^{+}$under condition (6.1).

Under condition (6.1) the dynamic map is continuous, monotonic, increasing and globally concave with $k \rightarrow+\infty \lim \frac{G(k)}{k}=0<1$ and $k \rightarrow 0 \lim G^{\prime}(k)=+\infty>1$. There thus exists a unique globally stable steady-state equilibrium ${ }^{7}$ The economy experiences a steady state with endogenous altruism if and only if: $\beta>\left(\frac{1+\gamma}{A}\right)^{\frac{1}{1-\alpha}} \gamma^{\frac{1-2 \alpha}{1-\alpha}}$.

\section{References}

Azariadis, Costas and Allan Drazen (1990): Threshold Externalities in Economic Development, Quarterly Journal of Economics, 105(2), 501-526.

Badinter, Elizabeth (1980): L'amour en plus: Histoire de l'amour maternel, XVII ${ }^{e}$ $X X^{e}$ siècle, Paris: Flammarion.

Barro, Robert J. (1974): Are government bonds net wealth?, Journal of Political Economy, 82, 1095-117.

Becker, Gary S. (1974): A Theory of Social Interactions, Journal of Political Economy, 82, 1063-93. Press.

Becker, Gary S. (1996): Accounting for Tastes, Cambridge, Ma.: Harvard University

Becker, Gary S. and Casey B. Mulligan (1997): The Endogenous Determination of Time Preference, Quarterly Journal of Economics, 729-58.

Becker, Gary S. and Kevin M. Murphy (1988): A theory of rational addiction, Journal of Political Economy, 96, 675-700.

Behrman, Jere R., Andrew D. Foster, Mark R. Rosenzweig and Prem Vashishtha (1999): Women's schooling, home teaching, and economic growth, Journal of Political Economy, 107, 4: 682-714.

Bianchi, Suzanne M. (2000): Maternal employment and time with children: dramatic change or surprising continuity?, Demography, 37, 4: 401-14.

Bisin, Alberto and Thierry Verdier (2000): Beyond the Melting Pot: Cultural Transmission, Marriage, and the Evolution of Ethnic and Religious Traits, Quarterly Journal of Economics, 955-988.

Bowles, Samuel (1998): Endogenous preferences: the cultural consequences of markets and other economic institutions, Journal of Economic Literature, 36, 75-111.

\footnotetext{
${ }^{7}$ Clearly, condition (6.1) always holds when $\alpha \leq 1 / 2$. Uniqueness and global stability are obtained for sensible parametric values.
} 
Brezis, Elise S. (2002): Fertility, non-altruism and economic growth: industrialization in the nineteenth century, Mimeo., Bar-Ilan University.

Brown, Lynn R. and Lawrence Haddad (1995): Time allocation patterns and time burdens: A gendered analysis of seven countries, Mimeo., Washington: International Food Policy Research Institute.

de la Croix, David and Philippe Michel (2001): Altruism and self-restraint, Annales d'Economie et de Statistique, 63-64, 233-260.

Duflo, Esther and Christopher Udry (2001): Risk and intrahousehold allocation in Cote d'Ivoire, Mimeo., MIT.

Galasso, Emanuela (1999): Intra-household allocation and child labor in Indonesia, Mimeo., Boston College.

Hirschman, Albert O. (1977): The passions and the interests: political arguments for capitalism before its triumph, Princeton: Princeton University Press.

Kochar, Anjini (2002): Schooling, wages and profits: Some negative pecuniary externalities from the spread of schooling in rural India and their consequences for schooling investments, Mimeo., Stanford University.

Malathy, R. (1992): Education and Women's time allocation to non-market work in an urban setting of India, Yale Economic Growth Center, Discussion Paper No 683.

Michel, Philippe, Emmanuel Thibault and Jean-Pierre Vidal (2003): Altruistic models of economic growth; in L.-A. Gerard-Varet, S.-C. Kolm and J. Mercier Ythier, eds.: Handbook on the Economics of Reciprocity, Giving and Altruism, Amsterdam: North Holland, forthcoming.

Michel, Philippe and Jean-Pierre Vidal (2003): Self-control and Savings, European Central Bank Working Paper No 211.

Mulligan, Casey B. (1997): Parental Priorities and Economic Inequality, Chicago: The University of Chicago Press.

Sandberg, John F and Sandra L. Hofferth (2001): Changes in children's time with parents: United States, 1981-1997, Demography, 38, 3: 423-36.

Seymour, Susan C. (1999): Women, family and child care in India, Cambridge, Mass: Cambridge University Press.

Thomas, Duncan (1990): Intra-household allocation: An inferential approach, Journal of Human Resources, 25, 4: 635-64.

Tocqueville, Alexis de (1840): Democracy in America, vol II. New York: Anchor Books, 1969.

World Bank (2001): World Development Report, Washington: The World Bank. 
Figure 1

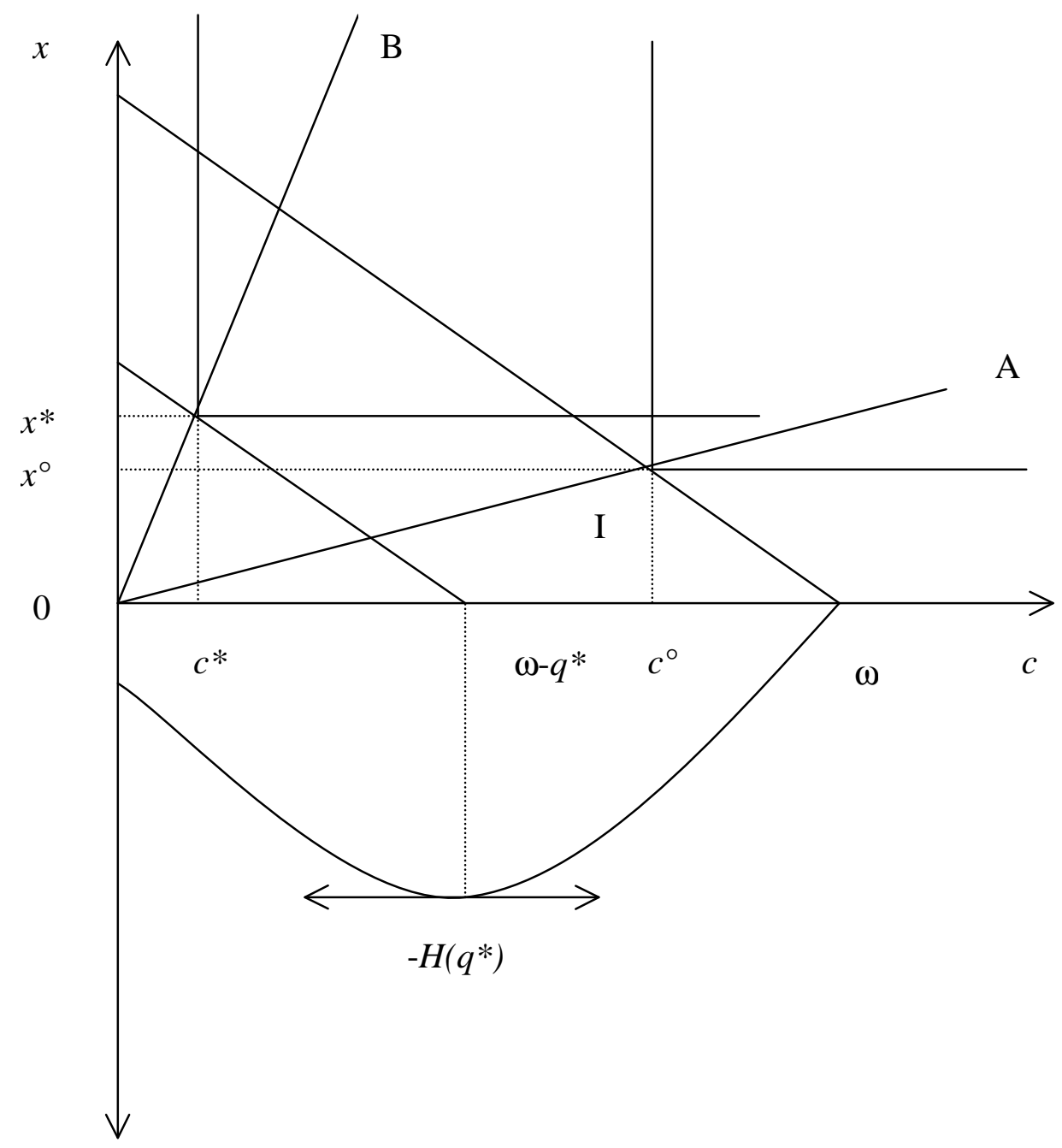


Figure 2

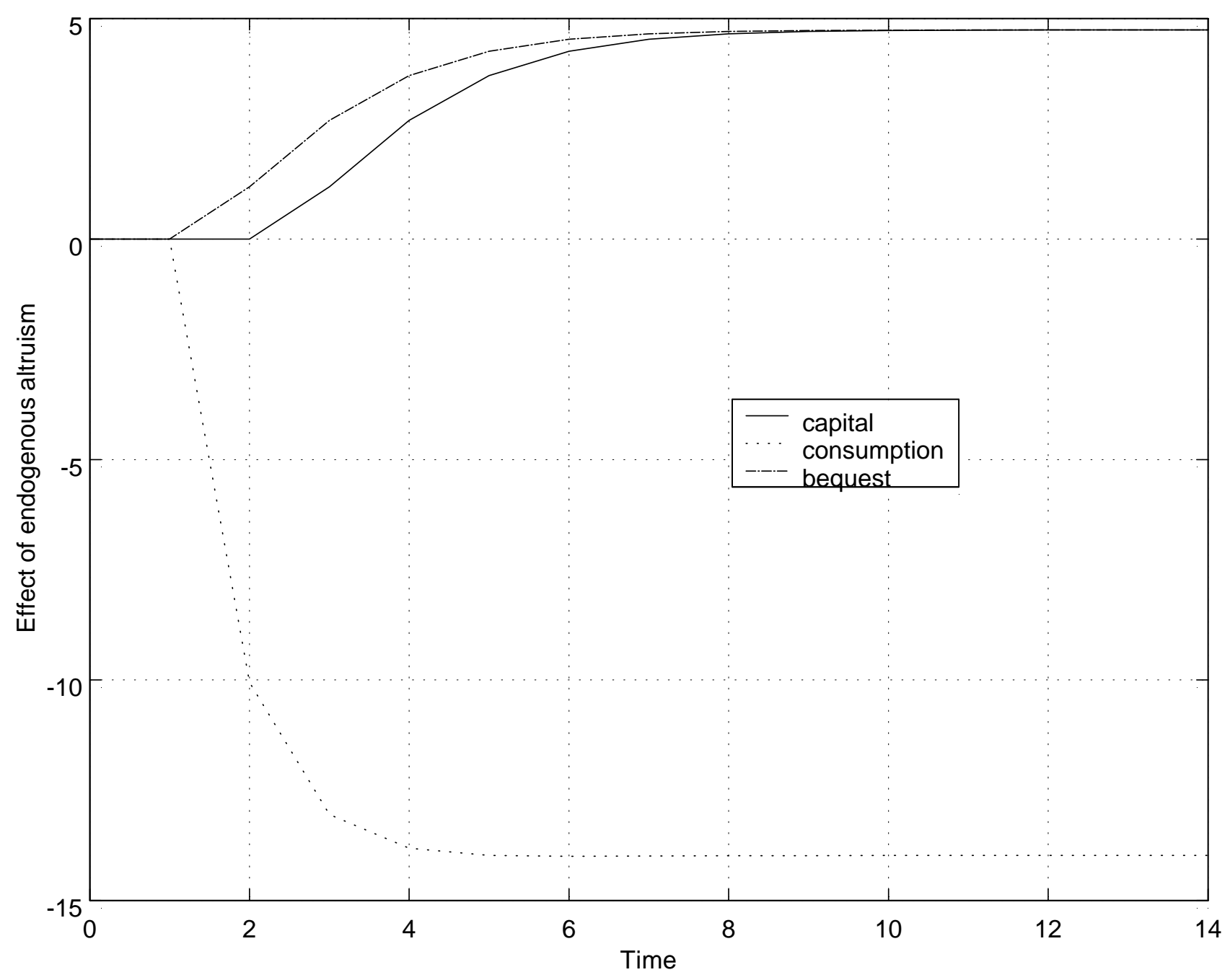




\section{Bar-Ilan University \\ Department of Economics \\ WORKING PAPERS}

1-01 The Optimal Size for a Minority

Hillel Rapoport and Avi Weiss, January 2001.

2-01 An Application of a Switching Regimes Regression to the Study

of Urban Structure

Gershon Alperovich and Joseph Deutsch, January 2001.

3-01 The Kuznets Curve and the Impact of Various Income Sources on the

Link Between Inequality and Development

Joseph Deutsch and Jacques Silber, February 2001.

4-01 International Asset Allocation: A New Perspective

Abraham Lioui and Patrice Poncet, February 2001.

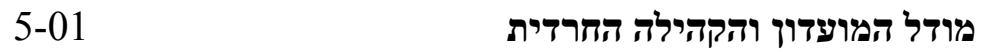

יעקב רוזנברג, פברואר 2001.

6-01 Multi-Generation Model of Immigrant Earnings: Theory and Application

Gil S. Epstein and Tikva Lecker, February 2001.

7-01 Shattered Rails, Ruined Credit: Financial Fragility and Railroad Operations in the Great Depression

Daniel A.Schiffman, February 2001.

8-01 Cooperation and Competition in a Duopoly R\&D Market

Damiano Bruno Silipo and Avi Weiss, March 2001.

9-01 A Theory of Immigration Amnesties

Gil S. Epstein and Avi Weiss, April 2001.

10-01 Dynamic Asset Pricing With Non-Redundant Forwards

Abraham Lioui and Patrice Poncet, May 2001.

Electronic versions of the papers are available at

http://www.biu.ac.il/soc/ec/wp/working_papers.html 
11-01 Macroeconomic and Labor Market Impact of Russian Immigration in Israel

Sarit Cohen and Chang-Tai Hsieh, May 2001.

12-01 Network Topology and the Efficiency of Equilibrium Igal Milchtaich, June 2001.

13-01 General Equilibrium Pricing of Trading Strategy Risk Abraham Lioui and Patrice Poncet, July 2001.

14-01 Social Conformity and Child Labor

Shirit Katav-Herz, July 2001.

15-01 Determinants of Railroad Capital Structure, 1830-1885

Daniel A. Schiffman, July 2001.

16-01 Political-Legal Institutions and the Railroad Financing Mix, 1885-1929 Daniel A. Schiffman, September 2001.

17-01 Macroeconomic Instability, Migration, and the Option Value of Education Eliakim Katz and Hillel Rapoport, October 2001.

18-01 Property Rights, Theft, and Efficiency: The Biblical Waiver of Fines in the Case of Confessed Theft

Eliakim Katz and Jacob Rosenberg, November 2001.

19-01 Ethnic Discrimination and the Migration of Skilled Labor

Frédéric Docquier and Hillel Rapoport, December 2001.

1-02 Can Vocational Education Improve the Wages of Minorities and Disadvantaged Groups? The Case of Israel

Shoshana Neuman and Adrian Ziderman, February 2002.

2-02 What Can the Price Gap between Branded and Private Label Products Tell Us about Markups?

Robert Barsky, Mark Bergen, Shantanu Dutta, and Daniel Levy, March 2002.

3-02 Holiday Price Rigidity and Cost of Price Adjustment

Daniel Levy, Georg Müller, Shantanu Dutta, and Mark Bergen, March 2002.

4-02 Computation of Completely Mixed Equilibrium Payoffs

Igal Milchtaich, March 2002. 
5-02 Coordination and Critical Mass in a Network Market An Experimental Evaluation

Amir Etziony and Avi Weiss, March 2002.

6-02 Inviting Competition to Achieve Critical Mass

Amir Etziony and Avi Weiss, April 2002.

7-02 Credibility, Pre-Production and Inviting Competition in a Network Market

Amir Etziony and Avi Weiss, April 2002.

8-02 Brain Drain and LDCs' Growth: Winners and Losers

Michel Beine, Fréderic Docquier, and Hillel Rapoport, April 2002.

9-02 Heterogeneity in Price Rigidity: Evidence from a Case Study Using Micro-Level Data

Daniel Levy, Shantanu Dutta, and Mark Bergen, April 2002.

10-02 Price Flexibility in Channels of Distribution: Evidence from Scanner Data Shantanu Dutta, Mark Bergen, and Daniel Levy, April 2002.

11-02 Acquired Cooperation in Finite-Horizon Dynamic Games Igal Milchtaich and Avi Weiss, April 2002.

12-02 Cointegration in Frequency Domain

Daniel Levy, May 2002.

13-02 Which Voting Rules Elicit Informative Voting?

Ruth Ben-Yashar and Igal Milchtaich, May 2002.

14-02 Fertility, Non-Altruism and Economic Growth:

Industrialization in the Nineteenth Century

Elise S. Brezis, October 2002.

15-02 Changes in the Recruitment and Education of the Power Elites in Twentieth Century Western Democracies

Elise S. Brezis and François Crouzet, November 2002.

16-02 On the Typical Spectral Shape of an Economic Variable Daniel Levy and Hashem Dezhbakhsh, December 2002.

17-02 International Evidence on Output Fluctuation and Shock Persistence Daniel Levy and Hashem Dezhbakhsh, December 2002. 
1-03 Topological Conditions for Unique ness of Equilibrium in Networks Igal Milchtaich, March 2003.

2-03 Is the Feldstein-Horioka Puzzle Really a Puzzle?

Daniel Levy, June 2003.

3-03 Growth and Convergence across the US: Evidence from County-Level Data

Matthew Higgins, Daniel Levy, and Andrew Young, June 2003.

4-03 Economic Growth and Endogenous Intergenerational Altruism

Hillel Rapoport and Jean-Pierre Vidal, June 2003. 